\title{
CONSADS DO BRASIL: UM ESTUDO A PARTIR DO ÍNDICE DE DESENVOLVIMENTO RURAL E DA ANÁLISE FATORIAL MÚLTIPLA
}

\author{
CONSADS of Brazil: A Study from Rural Development Index and Multiple Analysis Factor
}

\begin{abstract}
RESUMO
Neste trabalho, objetivou-se analisar a trajetória do desenvolvimento rural nos municípios pertencentes ao Consórcio de Segurança Alimentar e Desenvolvimento Local (CONSAD) do Brasil, nos anos 2000 e 2010, para isso, utilizaram-se dois métodos: o índice de desenvolvimento rural e análise fatorial múltipla, a fim de mensurar e comparar o desenvolvimento dos CONSADs, no intuito de analisar a evolução dessas localidades com a implementação do programa e sugerir políticas futuras e novos estudos em relação ao tema. O índice de desenvolvimento rural está relacionado com a população, bem-estar social, desenvolvimento econômico e meioambiente. Os resultados indicam que, de modo geral, o programa CONSAD foi benéfico para seus municípios, ou seja, houve um aumento no Índice de Desenvolvimento Rural em quase todos os CONSADs do Brasil, durante os anos 2000 e 2010; em relação aos subíndices a evolução foi diferente entre as regiões, o subíndice populacional teve evolução apenas na região Centro-Oeste; já o de desenvolvimento econômico evoluiu na região Sul e o de meio ambiente aumentou na região Norte. O único subíndice que evoluiu em todas as regiões foi o de bem-estar social, mostrando que a estratégia do CONSAD de formar capital humano foi benéfica para todos os CONSADs do Brasil.
\end{abstract}

Aline Claro Polastrini

Universidade Federal do Mato Grosso do Sul

aline_polastrini@hotmail.com

Matheus Wemerson Gomes Pereira

Universidade Federal de Viçosa

matheuswgp@yahoo.com.br

Recebido em: 01/03/2017. Aprovado em: 27/11/2018.

Avaliado pelo sistema double blind review

Avaliador científico: Renato Silvério Campos

DOI: 10.21714/2238-68902018v20n2p114

\begin{abstract}
The objective of this study is to analyze the rural development trajectory in the municipalities belonging to the Consortium on Food Security and Local Development (CONSAD) in Brazil in the years 2000 and 2010, using two methods: the rural development index and factorial analysis, in order to measure and compare the development of the CONSADs and to analyze the evolution of these localities with the implementation of the program, suggesting future policies and new studies in relation to the theme. The rural development index is related to population, social welfare, economic development, and the environment. The results indicate that, in general, the CONSAD program was beneficial to its municipalities, with an increase in the Rural Development Index in almost all CONSADs in Brazil during the years 2000 and 2010. As for the subindices, the evolution was different between the regions. The sub index was only developed in the Center-West region. The South region presented evolved economic development and the North region presented increased environment. The only sub index that has evolved in all regions was social welfare, showing that CONSAD's strategy for building human capital was beneficial to all CONSADs in Brazil.
\end{abstract}

Palavras-chave: Desigualdade, Trajetória, Desenvolvimento Rural.

Keywords: Inequality, Trajectory, Rural Development.

\section{INTRODUÇÃO}

No decênio que compreende os anos de 2002 e 2012, a pobreza decaiu 57,4\% no Brasil. Em termos absolutos foram 22,5 milhões de pessoas que deixaram a condição de pobreza, uma vez que passou de 39,3 milhões de brasileiros, vivendo com até 140 reais mensais per capita de rendimento domiciliar em 2002 para 16,7 milhões de brasileiros em 2012 (PNAD, 2013). Porém, essa redução apresenta tendências locais diferenciadas, resultando, até mesmo, na concentração da pobreza em certas microrregiões do país (SILVA; LEITE, 2014). A corrente do Estado de bem-estar social defende que o atraso econômico e a pobreza só podem ser interrompidos, por meio de intervenções do Estado que promovam crescimento econômico com integração nacional. 
De acordo com Riani (2009), o governo tem papel fundamental na realização de atividades de cunho intervencionista nas relações existentes na sociedade. Essa atuação é decorrente das "Falhas de Mercado", situação na qual a simples interação entre consumidores e produtores não leva a melhor alocação possível dos recursos econômicos. Como solução a essas "falhas" o governo intervém na economia, por meio de três funções básicas: 1) Função alocativa, atribui ao Estado a responsabilidade pela alocação dos recursos existentes na economia quando, pela livre iniciativa de mercado, isso não ocorrer; 2) Função distributiva, por meio de políticas públicas visa a conceder benefícios às famílias de menor poder aquisitivo; e 3) Função estabilizadora, com objetivo de manter a estabilidade econômica, associada à execução de suas políticas econômicas, estas tradicionalmente divididas em política fiscal e política monetária.

Um dos programas do governo federal atribuído na função alocativa e distributiva são os Consórcios de Segurança Alimentar e Desenvolvimento Local (CONSAD), criados em 2003, pertencentes ao programa Fome Zero do Governo Federal, como parte integrante da estratégia do Ministério do Desenvolvimento Social e Combate à Fome (PRADO, 2011). No Brasil, estão implantados quarenta CONSADs, distribuídos em vinte e seis estados, envolvendo quinhentos e oitenta e cinco municípios e uma população de mais de onze milhões de habitantes. Estão distribuídos sete CONSADs no Norte, doze no Nordeste, cinco no Centro-Oeste, oito no Sudeste e oito no Sul (MDS, 2004).

O CONSAD visa ao fortalecimento e ampliação das ações de segurança alimentar e nutricional e de desenvolvimento local nas áreas de maiores necessidades do país, adotando políticas estruturais capazes de aumentar as oportunidades de geração de emprego e renda disponíveis nos municípios carentes, mas será que houve melhoria em termos de desenvolvimento nos municípios pertencentes aos CONSAD entre os períodos de 2000 a 2010? Esta pesquisa procura identificar se realmente houve um desenvolvimento desses municípios com a implantação do programa CONSAD, por meio do índice de desenvolvimento rural que está relacionado aos aspectos de bem-estar, desenvolvimento econômico, população e meio ambiente.

A utilização de indicadores apresenta-se imprescindível como instrumento operacional para o monitoramento da realidade social para fins de formulação e reformulação de políticas públicas, que auxiliam no trabalho de planejamento, implementação, execução, avaliação dos programas, projetos e serviços sociais (JANUZZI, 2001). Eles se prestam a subsidiar as atividades de planejamento público e formulação de políticas nas diferentes esferas de governo, possibilitam o monitoramento das condições de vida, da conjuntura econômica e qualidade de vida da população.

Os indicadores para avaliação de políticas sociais são importantes para decisões sobre a manutenção ou interrupção das ações. É um instrumento importante para a melhoria da eficiência do gasto público, da qualidade, da gestão e do controle sobre a efetividade da ação do Estado, bem como para a divulgação de resultados de governo (CUNHA, 2006). Por meio dele, é possível verificar se o recurso investido está ocasionando retorno para a população.

Sendo assim, este trabalho procura mensurar a eficiência do programa CONSAD por meio da mensuração do desenvolvimento rural dos municípios pertencentes ao programa, para isso, o objetivo deste trabalho foi analisar a trajetória do desenvolvimento rural nos municípios pertencentes aos Consórcios de Segurança Alimentar e Desenvolvimento Local (CONSAD) do Brasil nos anos 2000 e 2010, por meio do Índice de Desenvolvimento Rural (IDR) e Analise Fatorial Múltipla (AFM), sendo possível avaliar a eficiência do programa e sugerir possíveis intervenções, o que torna esse trabalho importante não apenas para a comunidade acadêmica, mas também para o poder público e os entes envolvidos no programa.

$\mathrm{O}$ texto está dividido em 5 seções. Sendo a primeira parte esta introdução, definindo o contexto, a problemática e o objetivo; a segunda é a fundamentação teórica, abordando o programa CONSAD e sua estrutura e a mensuração do desenvolvimento rural. $\mathrm{Na}$ terceira seção, apresenta-se a metodologia, com o objetivo de esclarecer a utilização do Índice de Desenvolvimento Rural e da Análise Fatorial Múltipla. Já na quarta seção, são apresentados os resultados obtidos, a fim de responder os objetivos previamente descritos neste estudo e analisar se o programa CONSAD gerou desenvolvimento nesses municípios.

\section{FUNDAMENTAÇÃO TEÓRICA}

A Pesquisa do Ministério do Desenvolvimento Social e Combate à Fome (MDS), de 2003, apontou municípios com baixo Índice de Desenvolvimento Humano (IDH) em todos os estados brasileiros. Com esse mapeamento, o MDS passou a construir institucionalidades capazes de mediar conflitos e agregar esforços para 
reorganizar esses territórios visando à inclusão social. Assim, foram criados os Consórcios de Segurança Alimentar e Desenvolvimento Local (CONSAD), de acordo com Prado (2011) a formação de Consórcios de Segurança Alimentar e Desenvolvimento Local era parte integrante da estratégia do MDS, no âmbito do Programa Fome Zero, que visava ao fortalecimento e ampliação das ações de segurança alimentar e nutricional e de desenvolvimento local nas áreas de maior necessidade do país.

Segundo Ortega (2007), em 2003, foram constituídos 40 CONSADs e os critérios para sua seleção foram apresentados pelo Instituto Brasileiro de Administração Municipal (IBAM) e pelo extinto Ministério Extraordinário de Segurança Alimentar e Combate à Fome (MESA), por meio do documento "Estudo de Localização Territorial de Potenciais CONSADs no País". De uma proposta de 62 potenciais CONSADs, foram implementados 40 , de acordo com os seguintes critérios: 26 deles constituídos em todos os Estados da União; 14 tendo como critério o atendimento das regiões Norte e Nordeste, CONSADs Interestaduais, os que tinham, na ocasião, o maior número de municípios com Cartão de Alimentação do Programa Fome Zero; e os localizados em mesorregiões diferenciadas do Ministério da Integração Nacional e do Ministério do Planejamento, Orçamento e Gestão. Como o programa pretende atender prioritariamente às regiões Norte e Nordeste, neste artigo, tem-se como hipótese que essas regiões irão apresentar maiores evoluções no período analisado (2000 a 2010).

A implementação dos CONSADs é feita com uma organização centrada num órgão de deliberação máxima, com características de Fórum e órgãos de nível decisório gerencial e operacional. O Fórum constitui-se, dessa maneira, numa instância máxima de participação e deliberação, com participação de dois terços de representantes da sociedade civil e um terço do poder público local. Além do Fórum, os CONSADs têm o Conselho Fiscal, que fiscaliza e aprova suas contas. Cabe ao Conselho do CONSAD a implementação das ações definidas pelo Fórum (MDS, 2004).

De acordo com a Guia do CONSAD do MDS (2004), as ações dos CONSADs estão voltadas em quatro áreas: formação de capital social local; formação de capital humano local; agregação de valor nas cadeias produtivas sub-regionais e a modernização do setor público local. A formação de capital social local significa incentivar a organização da sociedade, a cooperação entre seus membros, fomentar espaços institucionais de negociação e gestão, entre outras atividades que fortaleçam os laços comunitários entre os habitantes de um determinado território.

Em relação à formação do capital humano é uma questão indispensável, pois os municípios pertencentes ao CONSAD possuem altos índices de analfabetismo e desqualificação profissional, decorrentes, em grande parte, da pobreza a qual estão submetidos. A intenção é incentivar a melhoria das condições educacionais, profissionais, técnicas e de acesso aos bens culturais locais. Já a agregação de valor nas cadeias produtivas subregionais significa disseminar técnicas e tecnologia para a produção local dos insumos necessários para a atividade produtiva dos micro e pequenos negócios, incentivar a troca de informações para conexão do maior número de produtores locais entre si e facilitar a comercialização dos produtos locais nos vários mercados. Desse modo, é fundamental que o poder público local seja modernizado em suas práticas e cultura gerencial, a fim de desempenhar seu papel insubstituível na estratégia de impulsionar o desenvolvimento local (MDS, 2004).

E na modernização do setor público local é preciso de um novo papel dessa esfera de poder para que este atue como um incentivador da construção de um pacto territorial e como fomentador de ações inovadoras de atores públicos e privados. Ou seja, a proposta do CONSAD coloca a sociedade civil local e poder público municipal lado a lado na promoção do desenvolvimento (JESUS, 2006).

Alguns exemplos de finalidades dos consórcios públicos são compras conjuntas (de uma licitação de vários contratos); agência reguladora regional; escola de Governo Regional; compartilhamento de equipamentos e de pessoal técnico; serviços conjuntos de abastecimento de água e esgotamento sanitário; unidades de saúde consorciais (hospitais, centros clínicos etc) e destinação final de resíduos sólidos (ORTEGA, 2007).

As ações dos CONSADs procuram desenvolver o meio rural onde estão inseridos os municípios. Para Kageyama (2004) desenvolvimento rural implica a criação de novos produtos e novos serviços, associados a novos mercados; procura formas de redução de custos a partir de novas trajetórias tecnológicas; tenta reconstruir a agricultura não apenas no nível dos estabelecimentos, mas em termos regionais e da economia rural como um todo. A pluriatividade das famílias rurais permite a retenção de população rural e redução do êxodo; e a diversidade das fontes de renda permite maior autonomia (menor dependência da atividade agrícola exclusiva) e menor instabilidade da renda. 
Uma das formas de mensurar o desenvolvimento rural em determinada região é por meio de indicadores. $\mathrm{O}$ indicador de desenvolvimento é uma medida normalmente quantitativa composta por um significado social, utilizado para suprir, mensurar, ou operacionalizar um conceito abstrato, de importância teórica (dentro de uma pesquisa acadêmica), ou pragmática (na formulação de políticas sociais). Não deixa de ser, da mesma forma, um recurso metodológico que ilustra uma característica da realidade social (JANUZZI, 2002). Segundo Melo (2005) os indicadores sociais são estatísticas importantes, pois possibilitam a comparação de situações entre localidades e entre períodos diferentes de um mesmo município, tornando-se, assim, uma forma de fiscalizar as condições sociais da população e subsidiar as atividades de planejamento público e formulação de políticas sociais nas diversas esferas governamentais.

\section{METODOLOGIA}

Este artigo utilizou dois métodos na análise da evolução dos CONSADs: Índice de Desenvolvimento Rural (IDR) e Análise Fatorial Múltipla (AFM), apresentadas nos itens 3.1 e 3.2, respectivamente.

\section{1 Índice de Desenvolvimento Rural (IDR)}

Primeiramente, foi calculado o Índice de Desenvolvimento Rural (IDR) de todos os CONSADs do Brasil. Considerando que o índice varia de 0 a 1 , sendo que quanto mais próximo de 1 melhor é o desenvolvimento na localidade.

A utilização do Índice de Desenvolvimento Rural foi proposto primeiramente pela Organização para a Cooperação e Desenvolvimento Econômico (OCDE) em 1996 no relatório "Territorial indicators of employment- Focusing on Rural Development", para descrever o desenvolvimento rural nas regiões dos seus países-membros.

Posteriormente, foi adaptada por Kageyama (2004), a qual afirma que obter todas as informações de acordo com o relatório da OCDE, a fim de construir esses indicadores em níveis regionais, somente é possível mediante grande esforço institucional voltado especificamente para o assunto. Caso o pesquisador esteja limitado pelas estatísticas disponíveis é quase que impossível espelhar essas medidas para todas as unidades territoriais elegidas.

No trabalho da Silva (2006), foram realizadas pequenas adaptações referentes às variáveis utilizadas para construir os indicadores em relação à proposta feita por
Kageyama (2004), especialmente os do meio ambiente e de bem estar social, em razão da disponibilidade de dados. E, posteriormente, o trabalho da Martins (2011) que realizou pequenas adaptações no índice de meio ambiente proposto por Silva (2006).

Neste trabalho, foi utilizado como base o trabalho da Martins (2011) para calcular o IDR dos municípios dos CONSADs do Brasil, o motivo da escolha deste trabalho é por ter sido o último estudo a realizar adaptações no IDR. Contudo, foram realizadas adaptações no índice proposto pela Martins (2011), principalmente nos indicadores populacional, bem-estar social e desenvolvimento econômico, tornando as variáveis mais atualizadas, possibilitando a comparação dos CONSADs entre os anos 2000 e 2010.

No Quadro 1, estão elencadas as variáveis utilizadas nesse índice. A construção dele é feita pela média aritmética de quatro índices: populacional, econômico, bem estar e ambiental. Cada um desses índices parciais é composto pela média aritmética de indicadores simples. A fórmula do índice é representa por:

$\mathrm{IDR}=(\mathrm{IPOP}+\mathrm{IBES}+\mathrm{IDE}+\mathrm{IMA}) / 4$

O primeiro índice é o referente a dados populacionais (IPOP), que têm o propóstio de medir a dinâmica da população do município. A ideia principal desse indicador é a de que, quanto maior for o nível de desenvolvimento rural, maior será o benefício para a dinâmica populacional.

Para compor o índice de população (IPOP), três variáveis foram utilizadas: densidade demográfica; proporção da população rural e taxa de envelhecimento. Quanto maior a densidade demográfica, menor o isolamento das áreas rurais e maiores as oportunidades de estabelecimento de redes sociais; quanto maior a população rural e seu crescimento, maior a capacidade da área rural de reter população (KEGEYMA, 2004); e quanto maior a taxa de envelhecimento melhores são as condições de vida da população.

O segundo índice é o de bem-estar social (IBES). Ele utiliza indicadores que buscam levantar aspectos referentes à educação (taxa de analfabetismo, crianças e adolescentes frequentando as escolas e quantidade de pessoas que já concluíram o ensino médio) e também variáveis referentes ao domicílio, importantes no sentido de fazer um levantamento sobre as condições de infraestrutura (domicílios com banheiro, água encanada e com energia elétrica). 
QUADRO 1 - Variáveis selecionadas para a construção do Índice de Desenvolvimento Rural.

\begin{tabular}{|c|c|c|c|c|}
\hline Índices & Variável & Forma de cálculo & $\begin{array}{c}\text { Forma de } \\
\text { mensuração }\end{array}$ & Base de dados \\
\hline \multirow{3}{*}{ População (IPOP) } & $\begin{array}{c}\text { a)Densidade } \\
\text { demográfica } \\
\text { (padronizada)* }\end{array}$ & $\begin{array}{l}\text { Proporção das pessoas (total) do } \\
\text { município, com relação ao seu } \\
\text { tamanho em } \mathrm{km}^{2}\end{array}$ & $\mathrm{Hab} . / \mathrm{km}^{2}$ & Censo 2000 e 2010 \\
\hline & $\begin{array}{l}\text { b) Proporção da } \\
\text { população rural }\end{array}$ & $\begin{array}{l}\text { Total da população rural do } \\
\text { município dividido pela sua } \\
\text { população total }\end{array}$ & Pessoas & $\begin{array}{c}\text { Atlas do Desenvolvimento } \\
\text { Humano no Brasil (2000 } \\
\text { e 2010) }\end{array}$ \\
\hline & $\begin{array}{l}\text { c) Taxa de } \\
\text { envelhecimento }\end{array}$ & $\begin{array}{l}\text { Razão entre a população de } 65 \text { anos } \\
\text { ou mais de idade e a população total. }\end{array}$ & Pessoas & $\begin{array}{c}\text { Atlas do Desenvolvimento } \\
\text { Humano no Brasil (2000 } \\
\text { e 2010) } \\
\end{array}$ \\
\hline \multirow{5}{*}{$\begin{array}{l}\text { Bem - Estar Social } \\
\text { (IBES) }\end{array}$} & $\begin{array}{l}\text { e) Taxa de } \\
\text { analfabetismo de } 15 \\
\text { anos ou mais }\end{array}$ & $\begin{array}{l}\text { População com } 15 \text { anos ou mais de } \\
\text { idade que não sabe ler nem escrever } \\
\text { dividido pelo total de pessoas nessa } \\
\text { faixa etária. }\end{array}$ & Pessoas & $\begin{array}{c}\text { Atlas do Desenvolvimento } \\
\text { Humano no Brasil (2000 } \\
\text { e 2010) }\end{array}$ \\
\hline & $\begin{array}{l}\text { f)Proporção de pessoas } \\
\text { de } 6 \text { a } 17 \text { anos na escola }\end{array}$ & $\begin{array}{l}\text { Pessoas com } 6 \text { a } 17 \text { anos de idade } \\
\text { que estava frequentando a escola, em } \\
\text { qualquer nível ou série, dividido pela } \\
\text { população total nesta faixa etária. }\end{array}$ & Pessoas & $\begin{array}{c}\text { Atlas do Desenvolvimento } \\
\text { Humano no Brasil (2000 } \\
\text { e 2010) }\end{array}$ \\
\hline & $\begin{array}{c}\text { g)Proporção de pessoas } \\
\text { com } 18 \text { anos ou mais } \\
\text { com ensino médio } \\
\text { completo }\end{array}$ & $\begin{array}{l}\text { Pessoas com } 18 \text { anos ou mais de } \\
\text { idade que concluiu o ensino médio } \\
\text { (regular, EJA ou supletivo) dividido } \\
\text { pelo total de pessoas nessa faixa } \\
\text { etária. }\end{array}$ & Pessoas & $\begin{array}{c}\text { Atlas do Desenvolvimento } \\
\text { Humano no Brasil (2000 } \\
\text { e 2010) }\end{array}$ \\
\hline & $\begin{array}{l}\text { h) Proporção da } \\
\text { população em domicílio } \\
\text { com banhiero e água } \\
\text { encanada }\end{array}$ & $\begin{array}{l}\text { População que vive em domicílio } \\
\text { particulares permanentes com água } \\
\text { encanada em pelo menos um de seus } \\
\text { comodos e com banheiro dividido } \\
\text { pela população total residente em } \\
\text { domicilio particulares permanentes. }\end{array}$ & Pessoas & $\begin{array}{c}\text { Atlas do Desenvolvimento } \\
\text { Humano no Brasil (2000 } \\
\text { e 2010) }\end{array}$ \\
\hline & $\begin{array}{l}\text { i) Proporção da } \\
\text { população em domicílio } \\
\text { com energia elétrica }\end{array}$ & $\begin{array}{l}\text { Razão entre a população que } \\
\text { vive em domicílios particulares } \\
\text { permanentes com iluminação elétrica } \\
\text { e a população total residente em } \\
\text { domicílios particulares permanentes. }\end{array}$ & Pessoas & $\begin{array}{c}\text { Atlas do Desenvolvimento } \\
\text { Humano no Brasil (2000 } \\
\text { e 2010) }\end{array}$ \\
\hline \multirow{3}{*}{$\begin{array}{l}\text { Desenvolvimento } \\
\text { Econômico (IDE) }\end{array}$} & j) PIB per capita* & $\begin{array}{c}\text { Produto Interno Bruto dividido pela } \\
\text { quantidade de habitantes }\end{array}$ & Reais & IBGE (2000 e 2010) \\
\hline & $\begin{array}{l}\text { k) Proporção de } \\
\text { empregados com } \\
\text { carteira assinada }-18 \\
\text { anos ou mais }\end{array}$ & $\begin{array}{l}\text { Número de empregados com } 18 \\
\text { anos ou mais de idade com carteira } \\
\text { de trabalho assinada dividido pelo } \\
\text { número de pessoas ocupadas nessa } \\
\text { faixa etária. }\end{array}$ & Pessoas & $\begin{array}{c}\text { Atlas do Desenvolvimento } \\
\text { Humano no Brasil (2000 } \\
\text { e 2010) }\end{array}$ \\
\hline & $\begin{array}{c}\text { 1) Proporção de } \\
\text { ocupados no setor } \\
\text { agropecuário - } 18 \text { anos } \\
\text { ou mais }\end{array}$ & $\begin{array}{l}\text { Número de pessoas de } 18 \text { anos ou } \\
\text { mais de idade ocupadas no setor } \\
\text { agropecuário dividido pelo número } \\
\text { total de pessoas ocupadas nessa faixa } \\
\text { etária. }\end{array}$ & Pessoas & $\begin{array}{c}\text { Atlas do Desenvolvimento } \\
\text { Humano no Brasil (2000 } \\
\text { e 2010) }\end{array}$ \\
\hline
\end{tabular}

Continua. 
QUADRO 1 - Continuação...

\begin{tabular}{|c|c|c|c|c|}
\hline \multirow{4}{*}{$\begin{array}{c}\text { Meio Ambiente } \\
\text { (IMA) }\end{array}$} & $\begin{array}{c}\text { m) Proporção de } \\
\text { estabelecimentos que } \\
\text { adotam práticas de } \\
\text { conservação do solo }\end{array}$ & $\begin{array}{c}\text { Total de estabelecimentos que } \\
\text { adotam práticas de conservação } \\
\text { do solo/ total de estabelecimentos } \\
\text { agropecuários }\end{array}$ & Unidade & Censo Agropecuário 2006 \\
\cline { 2 - 5 } & $\begin{array}{c}\text { n) Proporção de } \\
\text { que ustam adubos e } \\
\text { fertilizantes }\end{array}$ & $\begin{array}{c}\text { Total de estabelecimentos que } \\
\text { utilizam adubos e fertilizantes } \\
\text { agrícolas, no município. }\end{array}$ & Unidade & Censo Agropecuário 2006 \\
\cline { 2 - 5 } & $\begin{array}{c}\text { o) Ausência de } \\
\text { monocultura }\end{array}$ & $\begin{array}{c}\text { 1-(proporção de áreas das } \\
\text { monoculturas selecionadas) }\end{array}$ & Hectares & $\begin{array}{c}\text { Sidra (IBGE) - 2000 e } \\
2010\end{array}$ \\
\hline
\end{tabular}

*A padronização é uma transformação algébrica com a finalidade de que o índice varie no intervalo de zero a um. Essa transformação é o quociente: (valor da variável - mínimo)/(máximo - mínimo)

Fonte: Adaptado de Martins (2011)

Quanto às características educacionais, o objetivo do primeiro desses indicadores é apontar os municípios das regiões que possuem baixas taxas de analfabetismo, o que levaria a um IDR mais alto (KAGEYAMA, 2004). Em seu cálculo, foi subtraída uma unidade do resultado, levando em conta que esta é uma variável negativa, ou seja, quanto menor a quantidade de indivíduos com 15 anos ou mais que não sabem ler nem escrever, melhor será a taxa de analfabetismo para um determinado município.

E as variáveis da população de 6 a 17 anos na escola e a quantidade de pessoas que concluiram o ensino médio refletem o perfil da população frente aos esforços de qualificação. É importante destacar que essas variáveis são referentes a toda população do município, uma vez que o IBGE não fornece tais dados de maneira discriminada, ou seja, população urbana e população rural. Dessa forma, poderia haver alguma discrepância quanto a real situação da população rural desses municípios, tendo em vista que o índice visa a captar o desenvolvimento rural da região de estudo.

O terceiro índice é o de desenvolvimento econômico (IDE). Por meio desse indicador, busca-se destacar o perfil do mercado de trabalho e do rendimento per capita do município. Para tanto, foram escolhidas três variavéis: renda per capita; empregados de 18 anos ou mais com carteira assinada; e ocupados no setor agropecuário com 18 anos ou mais.

O último indicador é o de meio-ambiente (IMA). $\mathrm{O}$ intuito desse indicador é destacar variáveis fundamentais para o desenvolvimento rural e a sua preservação. Mas existe certa complexidade, em decorrência da indisponibilidade de dados recentes e a dificuldade de adquirir informações mais completas sobre a qualidade do meio ambiente no meio rural para todos os municípios (SILVA, 2006).

De acordo com Silva (2006), o primeiro componente desse indicador consiste na proporção dos estabelecimentos que utilizam práticas de conservação do solo. A finalidade é verificar as condições e a conscientização dos agricultores em usar técnicas destinadas a esse fim, seja para garantir uma maior adequação dos solos à atividade agrícola ou prevenir contra os efeitos da mecanização. A expectativa é que as atividades relacionadas à agricultura familiar apontem para um maior índice de conservação do solo.

$\mathrm{O}$ segundo indicador refere-se à proporção de estabelecimentos que utilizam fertilizantes e adubos. A utilização abusiva associa-se a possíveis danos ambientais decorrentes do uso indiscriminado de agrotóxicos e da mecanização. $\mathrm{O}$ argumento implícito é que há um maior impacto ambiental resultante das técnicas de lavouras intensivas em monoculturas e altamente mecanizadas. Assim, espera-se que no âmbito das atividades praticadas pela agricultura familiar, o uso de fertilizantes e adubos seja menos intenso vis a vis às culturas típicas aos estabelecimentos de grande escala (SILVA, 2006).

Para o cálculo da variável proporção de estabelecimentos que utilizam fertilizantes e adubos, subtraiu-se uma unidade do resultado, já que esta é uma variável negativa, ou seja, quanto menor o uso de adubos e fertilizantes, menores são os impactos ambientais (MARTINS, 2011).

O último componente desse indicador esta relacionado à ausência de monocultura. A ideia sugere que a presença de atividades relacionadas com as monoculturas implica no maior uso de tecnologias químicas (defensivos, adubos e outros), em grande escala. Já na agricultura familiar as atividades agrícolas 
praticadas tendem a ser mais diversificadas. Segundo Silva (2006), espera- se que haja maior presença de agricultura familiar quanto maior for o indicador de ausência de monocultura. Consequentemente, quanto maior for o IMA, menor a tendência de monocultura no município e maior tende a ser a adoção de práticas de conservação do solo.

Após o cálculo do IDR dos anos 2000 e 2010 para todos os municípios pertencentes aos CONSADs, foi utilizada também à análise fatorial múltipla, a fim de analisar a trajetória do desenvolvimento dos municípios e agrupá-los de acordo com a semelhança de evolução nos anos analisados.

\subsection{Análise Fatorial Múltipla (AFM)}

Em termos gerais, a Análise Fatorial aborda o problema de analisar a estrutura das inter-relações (correlações) entre um grande número de variáveis definindo um conjunto de dimensões latentes comuns, chamadas de fatores. Com a Análise Fatorial o pesquisador pode primeiro identificar as dimensões separadas da estrutura e então determinar o grau em que cada variável é explicada por cada dimensão. Ao resumir os dados, a análise fatorial obtém dimensões latentes que, quando interpretadas e compreendidas, descrevem os dados em um número muito menor de conceitos do que as variáveis individuais (HAIR JUNIOR et al, 2005).

A AFM consiste em analisar as observações descritas em conjuntos de variáveis e é realizada em duas etapas. Primeiramente, emprega-se a análise de componentes principais (ACPs) em cada conjunto de dados, os quais são normalizados, dividindo todos os seus elementos pela raiz quadrada do primeiro autovalor obtido da ACP. Em segundo lugar, os conjuntos de dados normalizados são agrupados para formar uma única matriz de ACP global.

O método garante que a importância relativa dos grupos seja equilibrada, de modo que nenhum deles possa determinar por si só a primeira direção principal da análise global. Os conjuntos de dados individuais são então projetados para a análise global, a fim de analisar comunalidades e discrepâncias. (ESCOFIER \& PAGÈS, 1984).

Na Figura 1, mostram-se as nuvens parciais e global de cada conjunto i associado a uma nuvem $\mathrm{Ni}$ de indivíduos situados no espaço Rk (PAGÉS, 2004). Ou seja, a partir das duas nuvens parciais forma-se uma nuvem global, mostrando as semelhanças entre as duas nuvens parciais.

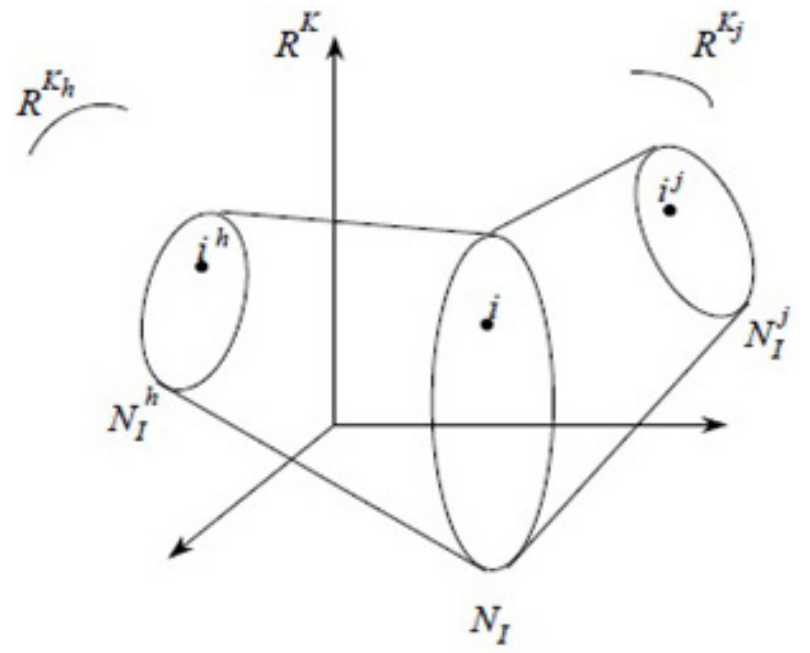

FIGURA 1 - Representação da AFM

Fonte: Pagés, 2004.

\subsubsection{Análise de Agrupamentos}

Tomando os escores fatoriais estimados por meio da análise fatorial múltipla, os agrupamentos foram construídos, utilizando-se a análise de agrupamentos ou clusters como forma de agrupar os CONSADs do Brasil de acordo com a semelhança de evolução entre eles nos anos 2000 e 2010. Além disso, a utilização dos escores fatoriais garante a ausência de colinearidade entre as variáveis e evita que variáveis colineares recebam maior peso na construção dos clusters (HAIR et al. 1995).

\section{RESULTADOS E DISCUSSÕES}

\section{1 Índice de Desenvolvimento Rural (IDR)}

O índice de desenvolvimento rural é composto pelos índices populacional, bem-estar social, desenvolvimento econômico e meio ambiente, sendo assim, primeiramente foi analisados cada um desses índices e depois o IDR geral.

\subsection{1 Índice Populacional (IPOP)}

Percebe-se, na Tabela 1, que apenas os CONSADs do Centro-Oeste tiveram um aumento no IPOP $(0,2 \%)$. Já os demais CONSADs tiveram uma diminuição, em razão da variável proporção da população rural que reduziu de 2000 a 2010 , ou seja, diminuiu a quantidade de pessoas morando na área rural, portanto houve uma redução da capacidade dos municípios em reter população rural,

Organizações Rurais \& Agroindustriais, Lavras, v. 20, n. 2, p. 114-133, 2018 
principalmente na região Sudeste que teve a maior queda no $\operatorname{IPOP}(-5,6 \%)$.

Mesmo a região Centro-Oeste apresentando uma evolução positiva no IPOP, é a região que obteve o menor índice populacional em 2010, e o maior foi a região Nordeste. Mostrando que, na região Nordeste, existe uma grande quantidade de pessoas morando na área rural, o CONSAD que teve o maior IPOP em 2010 foi Brumado na Bahia e o menor foi o Rio Sul no Rio de Janeiro.

Em termos de variação de 2000 a 2010 o CONSAD que teve o maior aumento no índice foi Médio Rio Branco em Roraima (20,4\%) e o que teve maior redução no índice foi o CONSAD Alto Acre (-20,2\%).

Conforme o MDS (2004), as regiões dos CONSADs são essencialmente rurais e excluídas do eixo de acumulação de riqueza. E por meio do resultado encontrado do IPOP mostra que os municípios estão deixando de ser essencialmente rurais, ou seja, a população rural está diminuindo e aumentando a população urbana, ocasionando uma dinamização econômica dos municípios.

Essa redução da população rural é provocada por diversos fatores advindos das várias transformações ocorridas na sociedade e no seu modo de produção, como: a) maior concentração industrial nas áreas urbanas (aumento da demanda de mão de obra); b) mudanças no processo produtivo na agricultura (abertura de fronteiras agrícolas, disponibilidade de crédito, especialização produtiva do processo agrícola etc.) ; c) fragilidade da oferta de bens e serviços pelo Estado no meio rural (saúde, educação, lazer, transporte etc.); d) escassez, penosidade e precariedade do trabalho no meio rural (que ainda persiste, apesar das grandes transformações tecnológicas e de normas e instrumentos legais); e) incremento do nível tecnológico das atividades rurais; f) diminuição de taxas de fecundidade, que reduziu sensivelmente a reposição da população; g) elevação da concentração da propriedade da terra, pela ausência de política nacional de reforma agrária (DIEESE, 2014).

Apenas os CONSADs Rio Branco (RR), Metropolitano Sul (RS), Entorno de Brasília (DF), Iguatemi (MS), Arari (PA), Baixada Cuiabana (MT) e Agreste Potiguar (RN) apresentaram aumento no IPOP de 2000 a 2010. A variação positiva do CONSAD Iguatemi (MS) corrobora com os resultados encontrados pela Martins (2011) de acordo com seus resultados o CONSAD Iguatemi foi o que obteve o maior IPOP médio no estado de Mato Grosso do Sul, seguido pelo CONSAD Vale do Ivinhema e, por último, o CONSAD Serra da Bodoquena.

\subsection{2 Índice de Bem-Estar Social (IBES)}

$\mathrm{Na}$ Tabela 1, mostra-se que todos os CONSADs tiveram aumento no IBES de 2000 a 2010, mostrando uma melhora no bem-estar social da população dos CONSADs, todas as variáveis pertencentes ao índice aumentaram, evidenciando uma melhora em termos educacionais e infraestrutura domiciliar. O IBES foi o que apresentou melhor performance dentre os índices analisados, corroborando com os resultados encontrados no trabalho de Silva (2006) que utilizou o IDR nos municípios beneficiados pelo Pronaf das regiões Nordeste e Sul, e dentre os indicadores analisados o que apresentou melhor performance, para ambas as regiões, foi o IBES.

Além disso, na Tabela 1, percebe-se que as regiões que tiveram um maior e menor índice, em 2010, foram a Sudeste e Norte, respectivamente, mas apesar da região Norte ter apresentado o menor valor, foi a região que mais evoluiu no bem- estar social durante os anos analisados (29,4\%). Em 2010, o CONSAD Rio Sul no Rio de Janeiro teve o maior IBES e o CONSAD Juruá, em Amazonas, teve o menor.

Em termos de evolução de 2000 a 2010 o CONSAD que obteve o maior aumento do índice foi o Brumado na Bahia (47,8\%). Isso mostra que a estratégia dos CONSADs de formação de capital humano está gerando resultados.

De acordo com o MDS (2004), os municípiosalvo do CONSAD são marcados por altos índices de analfabetismo, desqualificação profissional e carências infraestruturais, decorrentes em grande parte da pobreza a qual estão submetidos. E pelos resultados encontrados percebe-se que houve uma melhora, durante os anos 2000 e 2010, no bem-estar social desses municípios. Observa-se que todos os CONSADs apresentaram evolução no IBES, sendo que as regiões Norte $(29,4 \%)$ e Nordeste $(28,4 \%)$ tiveram as maiores evoluções.

\subsection{3 Índice Desenvolvimento Econômico (IDE)}

$\mathrm{Na}$ Tabela 1, percebe-se que aumentou o IDE apenas na região Sul, já nas outras regiões o índice diminuiu de 2000 a 2010, isso é decorrente da variável, ocupados no setor agropecuário que reduziu em todos os CONSADs, ou seja, o CONSAD reduziu o emprego no setor agropecuário, em razão da mecanização, porém houve um aumento de empregados com carteira assinada em outros setores, cumprindo o objetivo de geração de renda nessas regiões. 


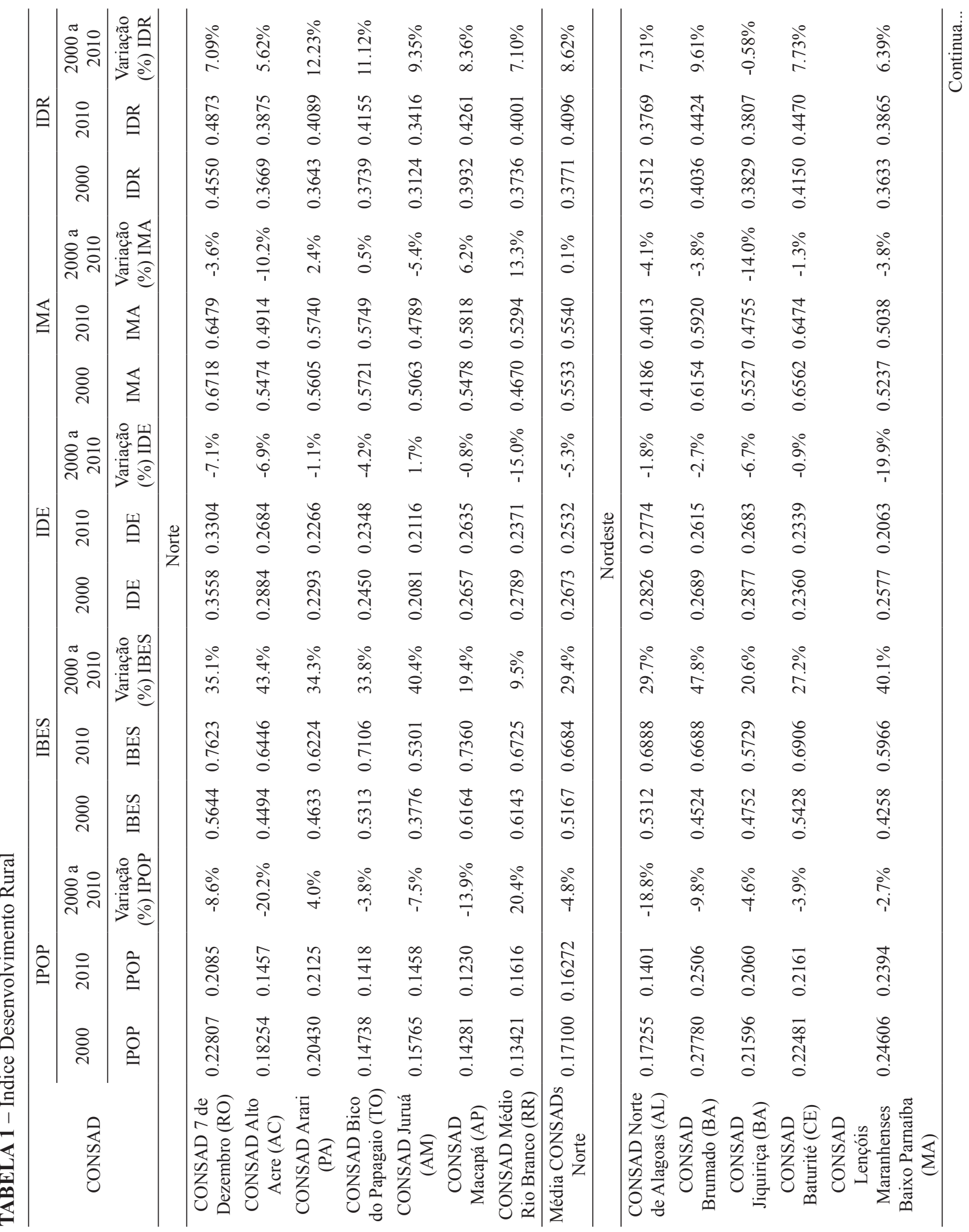

Organizações Rurais \& Agroindustriais, Lavras, v. 20, n. 2, p. 114-133, 2018 


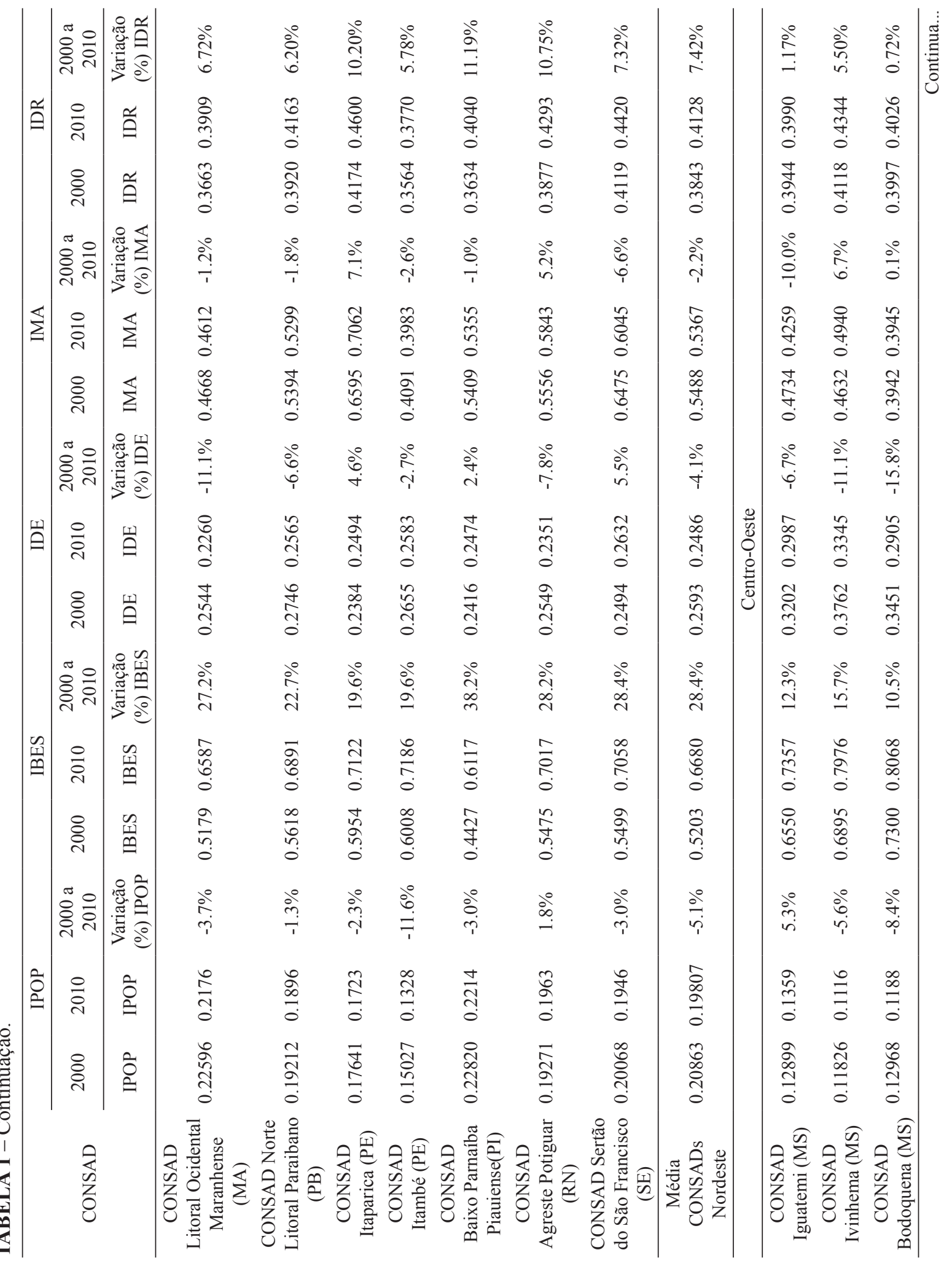

Organizações Rurais \& Agroindustriais, Lavras, v. 20, n. 2, p. 114-133, 2018 


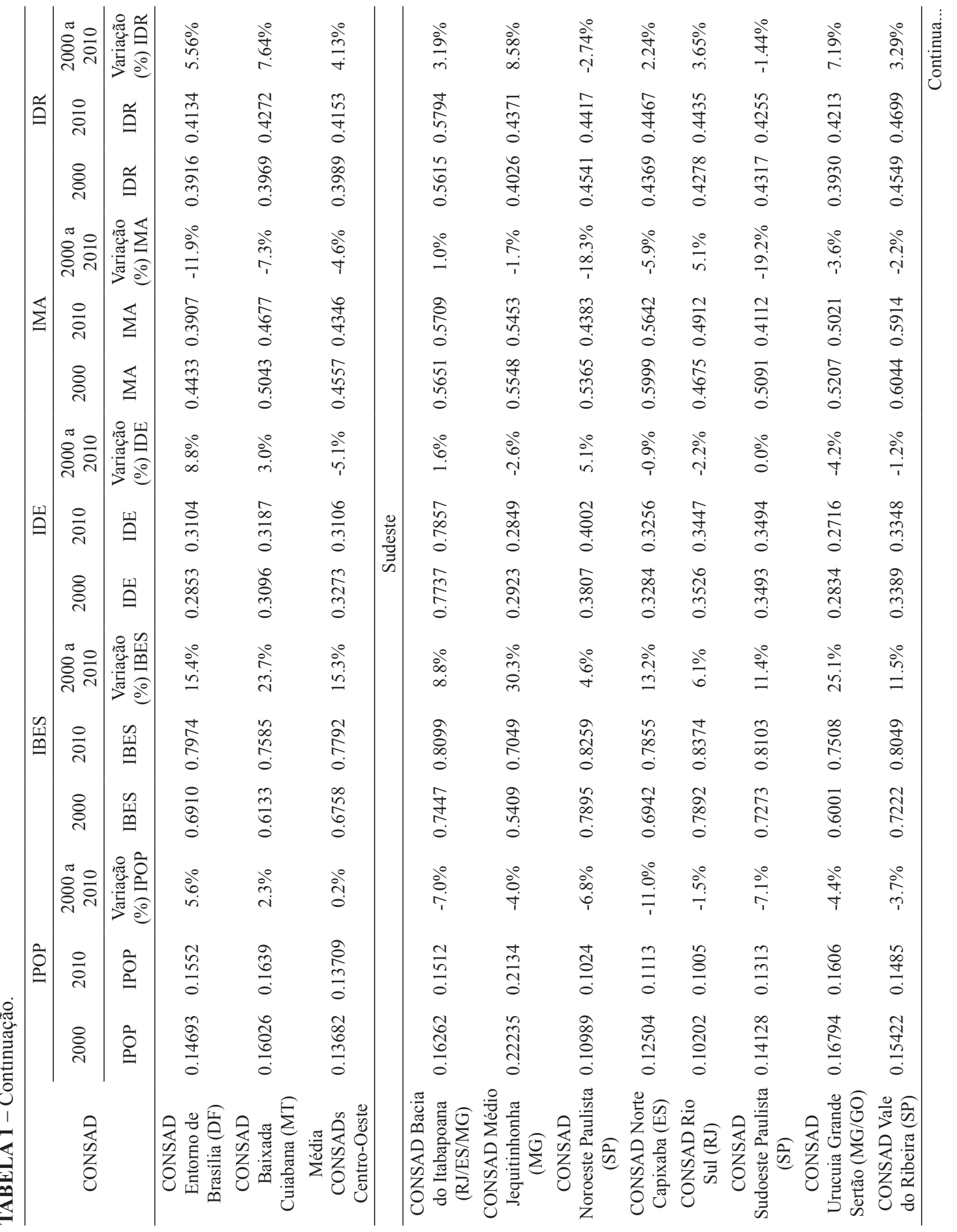

Organizações Rurais \& Agroindustriais, Lavras, v. 20, n. 2, p. 114-133, 2018 


\begin{tabular}{|c|c|c|c|c|c|c|c|c|c|c|c|c|c|}
\hline & 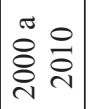 & 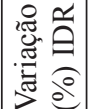 & 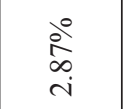 & & 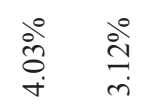 & $\stackrel{\stackrel{0}{+}}{\stackrel{0}{i}}$ & ठ̊. & هัं & $\begin{array}{l}\dot{0} \\
\dot{\alpha} \\
\text { in }\end{array}$ & $\stackrel{\circ}{\dot{m}}$ & $\frac{\partial^{\circ}}{\stackrel{r}{r}}$ & $\stackrel{\stackrel{0}{\infty}}{\stackrel{+}{+}}$ & 守 \\
\hline 覓 & $\stackrel{ }{\circ}$ & 荅 & $\begin{array}{l}\vec{\infty} \\
\stackrel{n}{0} \\
0\end{array}$ & & \begin{tabular}{ll}
$\stackrel{+}{\infty}$ & \multirow{+}{+}{} \\
$\stackrel{+}{+}$ & $\stackrel{+}{+}$
\end{tabular} & 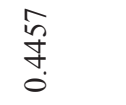 & $\begin{array}{l}\stackrel{2}{\circ} \\
\stackrel{5}{\circ} \\
0\end{array}$ & 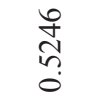 & $\underset{\stackrel{\sigma}{+}}{\stackrel{0}{0}}$ & ڤू & 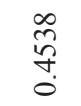 & $\begin{array}{l}\stackrel{0}{2} \\
\frac{n}{5} \\
0\end{array}$ & $\begin{array}{l}\infty \\
\stackrel{\infty}{7} \\
\stackrel{+}{0}\end{array}$ \\
\hline &  & 菅 & 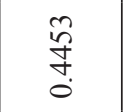 & & 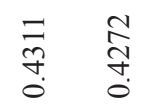 & 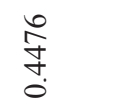 & ঙे & $\begin{array}{l}0 \\
\stackrel{\circ}{+} \\
0 \\
0\end{array}$ & 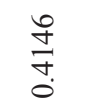 & $\frac{n}{n}$ & 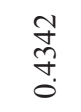 & 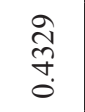 & 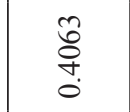 \\
\hline & 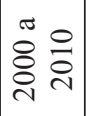 & 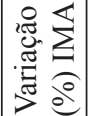 & $\begin{array}{l}\dot{b}_{0}^{0} \\
\dot{i}\end{array}$ & & $\frac{\partial}{+} \quad \frac{\stackrel{0}{i}}{1}$ & $\stackrel{\stackrel{\circ}{?}}{=}$ & $\stackrel{\stackrel{0}{i}}{i}$ & ڤें & $\begin{array}{l}\stackrel{0}{0} \\
\infty \\
\text { iे }\end{array}$ & $\stackrel{\stackrel{0}{i}}{\dot{p}}$ & $\stackrel{\text { ò }}{\stackrel{i}{i}}$ & $\frac{\partial}{\dot{r}}$ & $\begin{array}{l}\stackrel{\circ}{0} \\
\stackrel{+}{+}\end{array}$ \\
\hline $\mathbb{s}$ & $\stackrel{\circ}{\circ}$ & 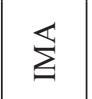 & $\frac{q}{n}$ & & 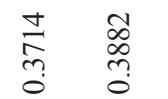 & 营 & 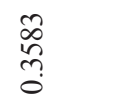 & 厄̂. &  & $\begin{array}{l}\stackrel{1}{n} \\
\tilde{0}\end{array}$ & 洜 & 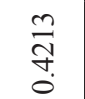 & \begin{tabular}{l} 
t \\
$\infty$ \\
\multirow{0}{0}{} \\
0
\end{tabular} \\
\hline & ๕ & 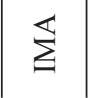 & 告 & & 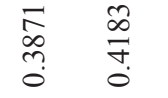 & $\begin{array}{l}0 \\
0 \\
0 \\
n \\
0\end{array}$ & \begin{tabular}{l}
$n$ \\
\multirow{0}{0}{} \\
$n$ \\
0
\end{tabular} & 触 & $\begin{array}{l}\text { d } \\
\text { in } \\
\text { o. } \\
0\end{array}$ & $\begin{array}{l}\text { ?ं } \\
0 \\
0 \\
0\end{array}$ & $\begin{array}{l}\overrightarrow{\widehat{\delta}} \\
\stackrel{0}{0}\end{array}$ & 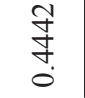 & $\begin{array}{l}8 \\
0 \\
0 \\
0 \\
0\end{array}$ \\
\hline & 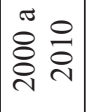 & 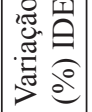 & $\frac{\circ}{0}$ & & 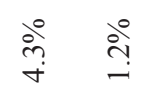 & बें & $\stackrel{\circ}{\stackrel{0}{I}}$ & in & $\frac{\stackrel{0}{i}}{i}$ & aे & 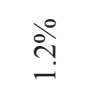 & ڤั̀ & $\frac{\stackrel{0}{0}^{2}}{i}$ \\
\hline 留 & $\stackrel{\circ}{\circ}$ & $\stackrel{\text { 崩 }}{=}$ & $\begin{array}{l}\overrightarrow{1} \\
\infty \\
0 \\
0\end{array}$ & $\overline{\vec{B}}$ & 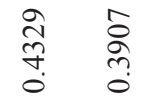 & 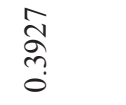 & $\underset{0}{\substack{++}}$ & 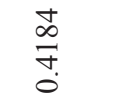 & $\begin{array}{l}\text { ते } \\
\tilde{n} \\
\tilde{0}\end{array}$ & 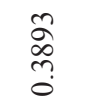 & $\begin{array}{l}0 \\
\tilde{2} \\
0\end{array}$ & ̊̊. & 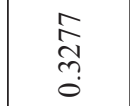 \\
\hline &  & 岒 & $\begin{array}{l}+1 \\
\infty \\
\vdots \\
0\end{array}$ & & 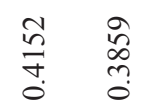 & 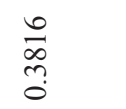 & 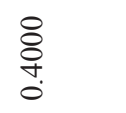 & 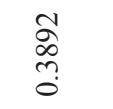 & 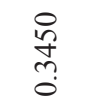 & 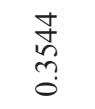 & $\begin{array}{l}\vec{\pi} \\
\infty \\
0 \\
0\end{array}$ & $\begin{array}{l}\tilde{a} \\
\infty \\
\vdots \\
0\end{array}$ & $\begin{array}{c}8 \\
\text { ֻे } \\
0\end{array}$ \\
\hline & $\begin{array}{ll}\pi & 0 \\
0 & 0 \\
0 & 0 \\
& 0\end{array}$ & 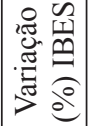 & $\stackrel{\text { ذे }}{\text { İ }}$ & & $\begin{array}{l}\stackrel{\circ}{\circ} \stackrel{\circ}{=} \\
\stackrel{]}{=}\end{array}$ & $\stackrel{\circ}{\circ}$ & $\stackrel{\stackrel{\circ}{\Xi}}{=}$ & $\stackrel{\circ}{\stackrel{0}{b}}$ & $\begin{array}{l}\stackrel{0}{0} \\
\dot{+}\end{array}$ & $\stackrel{\stackrel{0}{\circ}}{\stackrel{i}{I}}$ & $\frac{0^{\circ}}{n}$ & 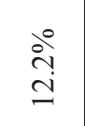 & $\begin{array}{l}\stackrel{0}{\infty} \\
\stackrel{-}{=}\end{array}$ \\
\hline $\mid$\begin{tabular}{l}
$n$ \\
1 \\
\hdashline \\
9
\end{tabular} & $\stackrel{\circ}{\circ}$ & 盐 & $\frac{2}{2}$ & & $\begin{array}{l}1 \\
0 \\
0 \\
0 \\
0\end{array}$ & $\begin{array}{l}F \\
\underset{\infty}{\infty} \\
0\end{array}$ & $\begin{array}{l}\stackrel{\leftrightarrow}{1} \\
\infty \\
0 \\
0\end{array}$ & $\begin{array}{l}n \\
\stackrel{1}{\infty} \\
0 \\
0\end{array}$ & $\begin{array}{l}\tilde{n} \\
\stackrel{0}{0} \\
0\end{array}$ & $\begin{array}{l}\text { ర్ర } \\
\stackrel{6}{0}\end{array}$ & $\begin{array}{l}\vec{\infty} \\
\stackrel{0}{0}\end{array}$ & $\begin{array}{l}\infty \\
\infty \\
\infty \\
0 \\
0\end{array}$ & $\stackrel{\vec{m}}{\stackrel{\leftrightarrow}{0}}$ \\
\hline & 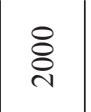 & $\begin{array}{l}\mathscr{y} \\
\dddot{y}\end{array}$ & $\frac{0}{2}$ & & $\begin{array}{ll}\stackrel{0}{0} & \frac{0}{2} \\
\stackrel{0}{0} & \stackrel{0}{0}\end{array}$ & $\begin{array}{l}\text { to } \\
\stackrel{2}{n} \\
\stackrel{0}{0}\end{array}$ & $\begin{array}{l}\infty \\
\stackrel{m}{0} \\
0\end{array}$ & $\begin{array}{l}\frac{1}{\infty} \\
\stackrel{\infty}{0}\end{array}$ & $\underset{\frac{1}{5}}{\frac{1}{0}}$ & $\begin{array}{l}n \\
n \\
n \\
0\end{array}$ & 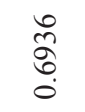 & $\begin{array}{l}\hat{\infty} \\
\hat{0} \\
0 \\
0\end{array}$ &  \\
\hline &  & 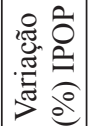 & $\begin{array}{l}\dot{0} \\
\dot{0}\end{array}$ & & $\begin{array}{l}\stackrel{0}{+} \\
\stackrel{1}{1}\end{array}$ & $\begin{array}{l}\stackrel{0}{0} \\
\stackrel{9}{1}\end{array}$ & $\begin{array}{l}\Delta_{0}^{0} \\
\text { के }\end{array}$ & $\stackrel{\circ}{\stackrel{0}{\circ}}$ & $\frac{8}{i}$ & $\stackrel{\circ}{\stackrel{p}{r}}$ & $\begin{array}{l}\stackrel{0}{\infty} \\
+†\end{array}$ & $\stackrel{\circ}{\stackrel{0}{+}}$ & $\stackrel{\stackrel{\circ}{+}}{+}$ \\
\hline $\mid$\begin{tabular}{l}
2 \\
0 \\
\hdashline
\end{tabular} & $\stackrel{\circ}{\circ}$ & 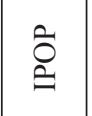 & 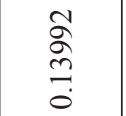 & & $\begin{array}{l}\stackrel{8}{\infty} \\
\stackrel{\infty}{0}\end{array}$ & $\begin{array}{l}\infty \\
\stackrel{0}{1} \\
\dddot{0}\end{array}$ & 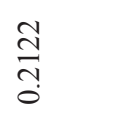 & 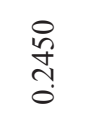 & 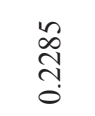 &  & 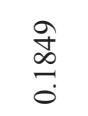 & $\begin{array}{l}\frac{1}{6} \\
\circ \\
\vdots \\
0\end{array}$ & 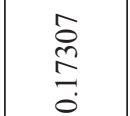 \\
\hline & ¿্ণ & $\begin{array}{l}\text { के } \\
\Leftrightarrow\end{array}$ & 竞 & & $\begin{array}{ll}\stackrel{n}{a} & \stackrel{f}{0} \\
\stackrel{0}{N} & \stackrel{5}{0}\end{array}$ & $\begin{array}{l}\text { E } \\
\stackrel{+}{0} \\
0\end{array}$ & $\begin{array}{l}\overrightarrow{0} \\
\text { त̂ } \\
0\end{array}$ & $\begin{array}{l}\stackrel{\curvearrowright}{\vec{N}} \\
\stackrel{0}{0}\end{array}$ & 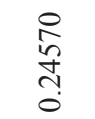 & 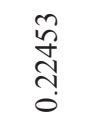 & 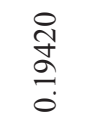 & 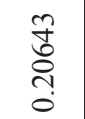 & $\begin{array}{l}\frac{8}{\infty} \\
\frac{\infty}{0} \\
0\end{array}$ \\
\hline & $\begin{array}{l}\text { 竞 } \\
\text { Ż } \\
0\end{array}$ & & 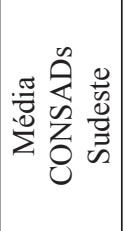 & & 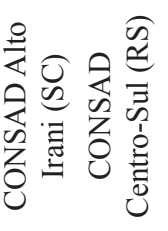 & 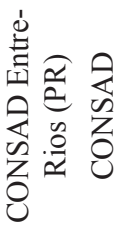 & 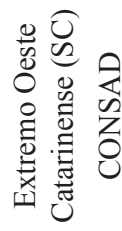 & 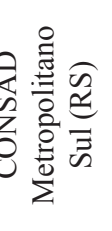 & 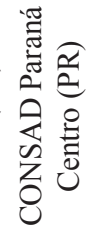 &  & 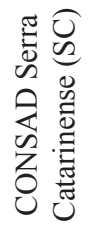 & 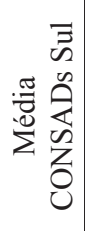 & 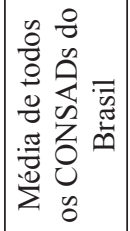 \\
\hline
\end{tabular}

Organizações Rurais \& Agroindustriais, Lavras, v. 20, n. 2, p. 114-133, 2018 
A diminuição da ocupação rural é reflexo das mudanças ocorridas no campo, que se caracterizam, entre outros aspectos, pela contínua especialização e mecanização do processo agrícola, com a consequente redução do número de postos de trabalho, uma das expressões mais visíveis da modernização da agricultura. Em 1970, por exemplo, havia pouco mais de $160 \mathrm{mil}$ tratores em operação no meio rural. Em 2013, eram quase 1,2 milhão. Ressalte-se a elevação de desempenho dessas máquinas, o que implica na demanda de uma mão de obra mais qualificada e escolarizada, ao mesmo tempo em que aumenta a produtividade do trabalho (DIEESE, 2014).

Em 2010, a região Sul teve o maior valor no IDE e entre todos os CONSADs o Bacia Itapoana (RJ/ES/MG) obteve o maior valor. E a região Nordeste teve o menor valor no IDE e o CONSAD que teve o menor índice foi Lençóis Maranhenses Baixo Parnaíba (MA). Na trajetória de 2000 a 2010 o CONSAD que teve o maior aumento no IDE foi o CONSAD Extremo Oeste Catarinense em Santa Catarina $(12,1 \%)$ e o CONSAD que mais reduziu o índice durante esses dez anos foi o CONSAD Lençóis Maranhenses Baixo Parnaíba (-19,9\%).

Uma das estratégias dos CONSADs é fortalecer e agregar valor as cadeias produtivas subregionais, que significa fortalecer as cadeias produtivas locais criando um circulo virtuoso de geração de trabalho, renda e consumo com base nos recursos humanos e produtivos locais (MDS, 2004). O IDE mostra que essa estratégia foi eficaz apenas em algumas regiões, como Nordeste, CentroOeste e Sul, pois tiveram evolução na renda per capita e empregados com carteira assinada. Já as regiões Sudeste e Norte tiveram apenas um aumento nos empregados com carteira assinada, mas na renda per capita tiveram uma queda no valor.

\subsection{4 Índice de Meio Ambiente (IMA)}

Apenas os CONSADs do Norte tiveram um pequeno aumento no IMA $(0,1 \%)$, as outras regiões diminuíram de 2000 a 2010, isso foi decorrente da variável ausência de monocultura que reduziu, evidenciando a adoção de uma ou poucas culturas "modernas" que são grandes consumidoras de agrotóxicos poluidoras do ar e/ ou empobrecedoras do solo. Isso evidência uma redução da agricultura familiar nesses municípios, mostrando que o programa do CONSAD não desempenhou a função de estimular a agricultura familiar nessas regiões, principalmente a região Sudeste que obteve a maior redução no IMA $(-5,6 \%)$.
Essa especialização em poucas culturas é extremamente prejudicial ao solo, acarretando significativo desequilíbrio ambiental, em razão do desgaste e empobrecimento nutricional causados pela produção contínua de uma mesma planta e a consequente contaminação, gerada pelo uso indiscriminado de fertilizantes, com o intuito de manter ou recuperar a produtividade da terra, e de agrotóxicos, indispensáveis para combater as pragas que surgem em razão da uniformização das culturas, prejudicando a segurança alimentar da população (ZIMMERMANN, 2009).

Em 2010, a região Norte teve os maiores valores no IMA, o CONSAD Itaparica (PE) obteve o maior valor dentre todos os CONSADs. E o menor valor foi a região Sul e dentre os CONSADs foi o CONSAD Missões (RS) que apresentou valor mais baixo. E na trajetória de 2000 a 2010 o CONSAD que teve o maior aumento foi CONSAD Médio Rio Branco de Roraima (13,3\%) e o que mais reduziu o valor foi o CONSAD Sudoeste Paulista (-19,2\%).

A única região que aumentou o índice de meio ambiente foi a Norte, dos sete CONSADs pertencentes a essa região, quatro tiveram evolução: CONSAD Médio Rio Branco (RR), Macapá (AP), Arari (PA) e Bico do Papagaio (TO), mostrando que houve uma evolução na agricultura familiar. A região Norte também teve os melhores valores em ausência de adubos e fertilizantes, evidenciando o baixo impacto ambiental nessa região. Já nas demais regiões do Brasil houve um retrocesso no IMA.

Fomentar a agricultura familiar significa melhorar as condições de acesso à alimentação por parte das famílias diretamente envolvidas na produção, possibilitar a ampliação da oferta de alimentos nos mercados municipais e gerar renda para os agricultores, mas para que a atividade de agricultura familiar e os arranjos socioprodutivos locais possam ser dinamizados como motores da economia do Desenvolvimento Local, é imprescindível que haja disponibilidade de crédito em condições adequadas para os agricultores familiares e micro empreendimentos (MDS, 2004).

\subsection{5 Índice de Desenvolvimento Rural (IDR)}

Na Tabela 1, é possível verificar os índices de desenvolvimento rural obtidos por cada CONSAD nos anos 2000 e 2010, e a porcentagem de variação do índice entre os dois anos, lembrando que esse índice é a média aritmética dos quatro índices apresentados anteriormente.

Analisando a média das regiões dos CONSADs, a mais desenvolvida é a região Sudeste, seguida pela Sul,

Organizações Rurais \& Agroindustriais, Lavras, v. 20, n. 2, p. 114-133, 2018 
Centro-Oeste, Nordeste e, por último, Norte. Apesar dessas últimas regiões apresentarem os menores IDR, foram as que obtiveram maiores aumentos na trajetória de 2000 a 2010, a região Norte aumentou 8,6\% e Nordeste 7,4\%. E a região Sudeste teve a menor evolução 2,8\%.

O CONSAD Bacia do Itabapoana, no sudeste, obteve o maior IDR nos dois anos analisados e o CONSAD Juruá na Amazonas teve o menor IDR também nos dois anos analisados, em razão do menor aumento no IBES, em termos de infraestrutura domiciliar e pessoas de 6 a 17 anos na escola e também obteve o menor valor na variável taxa de envelhecimento do IPOP.

Além disso, é possível identificar que alguns CONSADs tiveram queda no desenvolvimento, durante os anos analisados, como o CONSAD Jiquiriça (BA), o Noroeste Paulista e Sudoeste Paulista (SP) e o Entre Rios (PR), mostrando que o programa CONSAD não foi benéfico para essas regiões.

O CONSAD que mais se desenvolveu foi Arari (PA) e nos dez primeiros CONSADs que tiveram maiores aumentos no IDR pertencem às regiões Norte e Nordeste, sendo assim, o programa do CONSAD foi benéfico, principalmente, para essas regiões impulsionando o desenvolvimento dessas localidades. Lembrando que a região Norte teve a maior evolução no IBES e IMA. Desse modo, aceita-se a hipótese deste trabalho em que os CONSADs das regiões Nordeste e Norte tenderiam a apresentar maior desenvolvimento durante os anos 2000 e 2010.

O programa do CONSAD tem como meta atender prioritarimente às regiões Nordeste e Norte, pois são regiões que tinham o maior número de muncípios com Cartão Alimentação do Programa Fome Zero e localizados em mesorregiões diferenciadas do Ministério da Integração Nacional e do Ministério do Planejamento, Orçamento e Gestão (MDS, 2004).

\subsection{Análise Fatorial Múltipla (AFM)}

Utilizando a Análise Fatorial Múltipla, foram gerados 14 fatores (Tabela 2), mas foram extraídos apenas 2 fatores com raízes características maior do que 1. A análise dos dois primeiros fatores do grupo de variáveis indica que estes foram responsáveis pela maior porcentagem da variabilidade acumulada $(56,41 \%)$.

Desse modo, foram consideradas apenas duas dimensões na análise, a contribuição de cada índice (população, bem-estar social, desenvolvimento econômico e meio ambiente) podem ser observados na Tabela 3.

Percebe-se que o índice bem-estar social e desenvolvimento econômico estão mais relacionados com a dimensão 1 e o índice de população e meio ambiente com a dimensão 2, isso significa que o bem-estar e o desenvolvimento econômico pertencem ao índice 1 e o populacional e meio ambiente pertencem ao índice 2 .

TABELA 2 - Autovalores e variância acumulada dos componentes

\begin{tabular}{cccc}
\hline Fatores & Autovalor & Variância (\%) & Variância Acumulada (\%) \\
\hline $\mathbf{1}$ & $\mathbf{2 . 7 7 1}$ & $\mathbf{3 9 . 3 6 1}$ & $\mathbf{3 9 . 3 6 1}$ \\
$\mathbf{2}$ & $\mathbf{1 . 2 0 1}$ & $\mathbf{1 7 . 0 5 4}$ & $\mathbf{5 6 . 4 1 5}$ \\
$\mathbf{4}$ & 0.746 & 10.599 & 67.014 \\
5 & 0.633 & 8.989 & 76.002 \\
6 & 0.518 & 7.357 & 83.359 \\
7 & 0.314 & 4.461 & 87.820 \\
8 & 0.224 & 3.182 & 91.002 \\
9 & 0.204 & 2.903 & 93.905 \\
10 & 0.14 & 1.995 & 95.900 \\
11 & 0.077 & 1.098 & 96.998 \\
12 & 0.073 & 1.041 & 98.038 \\
13 & 0.063 & 0.899 & 98.937 \\
14 & 0.049 & 0.695 & 99.633 \\
\hline
\end{tabular}

Fonte: Elaborado pela autora, segundo resultados da pesquisa. 
TABELA 3 - Contribuições dos índices nas dimensões

\begin{tabular}{ccc}
\hline Índice & Dim 1 & Dim 2 \\
População & 26.319 & $\mathbf{4 7 . 8 0 7}$ \\
Bem Estar Social & $\mathbf{2 7 . 4 7 0}$ & 6.638 \\
Desenvolvimento Econômico & $\mathbf{3 0 . 1 3 8}$ & 21.575 \\
Meio Ambiente & 16.074 & $\mathbf{2 3 . 9 8 0}$ \\
\hline
\end{tabular}

Fonte: Elaborado pela autora, segundo resultados da pesquisa.

A trajetória dos CONSADs pode ser analisadas na Tabela 4, na dimensão 1 (bem-estar e desenvolvimento econômico) houve um aumento nos CONSADs de
2000 a 2010, ou seja, os CONSADs apresentaram uma melhora nesses dois aspectos, corroborando com IDR em que todos os CONSADs tiveram um aumento no IBES. Já na dimensão 2 (populacional e meio ambiente) alguns CONSADs tiveram uma queda, isso está associado a uma redução da população rural e um aumento da utilização de monocultura nessas localidades demonstrado no IDR.

Percebe-se pela AFM que, na dimensão 1, os CONSADs da região Sul tiveram maior variação de 2000 a 2010, seguido pelo Nordeste, corroborando com IDR apresentados na seção 4.2, onde a região Sul teve maior variação no IDE e o Nordeste no IBES.

TABELA 4 - Trajetória do desenvolvimento dos CONSADs entre 2000 e 2010

\begin{tabular}{|c|c|c|c|c|c|c|}
\hline \multirow{2}{*}{ CONSAD } & \multicolumn{2}{|c|}{2000} & \multicolumn{2}{|c|}{2010} & \multicolumn{2}{|c|}{ Variação } \\
\hline & Dim 1 & $\operatorname{Dim} 2$ & Dim 1 & $\operatorname{Dim} 2$ & Dim 1 & $\operatorname{Dim} 2$ \\
\hline & \multicolumn{6}{|c|}{ CONSADs Norte } \\
\hline CONSAD 7 de Dezembro (DD) & -1.623 & -0.205 & -0.499 & -0.154 & 1.124 & 0.051 \\
\hline CONSAD Alto Acre (AC) & -2.648 & -1.159 & -0.795 & -1.468 & 1.854 & -0.309 \\
\hline CONSAD Arari (AR) & -2.821 & -0.883 & -2.106 & -0.458 & 0.714 & 0.425 \\
\hline CONSAD Bico do Papagaio (BD) & -1.696 & -0.491 & -0.160 & -0.579 & 1.536 & -0.088 \\
\hline CONSAD Juruá (JU) & -3.192 & -1.315 & -2.139 & -1.055 & 1.053 & 0.260 \\
\hline CONSAD Macapá (MA) & -0.589 & -1.304 & 0.341 & -1.425 & 0.930 & -0.121 \\
\hline CONSAD Médio Rio Branco (MR) & -1.353 & -1.639 & -1.181 & -1.530 & 0.173 & 0.109 \\
\hline \multirow[t]{2}{*}{ Média CONSADs Norte } & -1.989 & -1.000 & -0.934 & -0.953 & 1.055 & 0.047 \\
\hline & \multicolumn{6}{|c|}{ CONSADs Nordeste } \\
\hline CONSAD Norte de Alagoas (NA) & -1.008 & -0.216 & 0.448 & -0.520 & 1.455 & -0.304 \\
\hline CONSAD Brumado (BR) & -2.759 & 1.037 & -0.727 & 1.250 & 2.032 & 0.213 \\
\hline CONSAD Jiquiriça (JI) & -1.751 & 0.783 & -0.734 & 1.050 & 1.017 & 0.266 \\
\hline CONSAD Baturité (BA) & -1.568 & 0.144 & -0.496 & 0.108 & 1.072 & -0.035 \\
\hline CONSAD Lençóis Maranhenses Baixo Parnaíba (LM) & -3.436 & 0.530 & -2.057 & 0.298 & 1.379 & -0.232 \\
\hline CONSAD Litoral Ocidental Maranhense (LO) & -2.610 & 0.257 & -1.372 & 0.277 & 1.237 & 0.020 \\
\hline CONSAD Norte Litoral Paraibano (NL) & -0.905 & 0.789 & 0.029 & 0.788 & 0.934 & 0.000 \\
\hline CONSAD Itaparica (IT) & -0.979 & 0.102 & -0.104 & 0.147 & 0.875 & 0.044 \\
\hline CONSAD Itambé (IA) & 0.062 & -1.014 & 1.130 & -0.998 & 1.068 & 0.016 \\
\hline CONSAD Baixo Parnaíba Piauiense(BP) & -3.001 & 0.136 & -1.491 & 0.181 & 1.510 & 0.045 \\
\hline CONSAD Agreste Potiguar (AP) & -0.811 & 0.533 & 0.202 & 0.538 & 1.013 & 0.006 \\
\hline CONSAD Sertão do São Francisco (SS) & -1.742 & 0.414 & -0.578 & 0.666 & 1.164 & 0.252 \\
\hline \multirow[t]{2}{*}{ Média CONSADs Nordeste } & -1.709 & 0.291 & -0.479 & 0.315 & 1.230 & 0.024 \\
\hline & \multicolumn{6}{|c|}{ CONSADs Centro-Oeste } \\
\hline CONSAD Iguatemi (IG) & -0.078 & -0.631 & 0.771 & -0.392 & 0.849 & 0.240 \\
\hline CONSAD Ivinhema (IV) & 0.130 & -1.265 & 0.947 & -1.073 & 0.817 & 0.192 \\
\hline
\end{tabular}

Organizações Rurais \& Agroindustriais, Lavras, v. 20, n. 2, p. 114-133, 2018 
TABELA 4 - Continuação

\begin{tabular}{|c|c|c|c|c|c|c|}
\hline \multirow{2}{*}{ CONSAD } & \multicolumn{2}{|c|}{2000} & \multicolumn{2}{|c|}{2010} & \multicolumn{2}{|c|}{ Variação } \\
\hline & $\operatorname{Dim} 1$ & $\operatorname{Dim} 2$ & Dim 1 & $\operatorname{Dim} 2$ & $\operatorname{Dim} 1$ & $\operatorname{Dim} 2$ \\
\hline CONSAD Bodoquena (BO) & 0.233 & -0.934 & 1.109 & -1.055 & 0.876 & -0.121 \\
\hline CONSAD Entorno de Brasília (EB) & 0.237 & -0.755 & 1.433 & -0.493 & 1.196 & 0.262 \\
\hline CONSAD Baixada Cuiabana (BC) & -0.505 & -0.900 & 0.797 & -0.476 & 1.302 & 0.424 \\
\hline \multirow[t]{2}{*}{ Média CONSADs Centro-Oeste } & 0.003 & -0.897 & 1.012 & -0.698 & 1.008 & 0.199 \\
\hline & \multicolumn{6}{|c|}{ CONSADs Sudeste } \\
\hline CONSAD Bacia do Itabapoana (BI) & 1.531 & 1.441 & 2.239 & 1.717 & 0.707 & 0.276 \\
\hline CONSAD Médio Jequitinhonha (MJ) & -1.824 & 0.569 & -0.344 & 0.749 & 1.480 & 0.181 \\
\hline CONSAD Noroeste Paulista (NP) & 2.043 & 0.002 & 3.212 & 0.312 & 1.169 & 0.310 \\
\hline CONSAD Norte Capixaba (NC) & 0.515 & -0.170 & 1.587 & -0.084 & 1.072 & 0.086 \\
\hline CONSAD Rio Sul (RS) & 2.350 & -1.800 & 2.927 & -1.641 & 0.578 & 0.159 \\
\hline CONSAD Sudoeste Paulista (SP) & 0.657 & -0.441 & 1.724 & -0.052 & 1.067 & 0.389 \\
\hline CONSAD Urucuia Grande Sertão (UG) & -1.024 & -0.111 & 0.241 & 0.097 & 1.265 & 0.208 \\
\hline CONSAD Vale do Ribeira (VR) & 0.571 & -0.658 & 1.565 & -0.268 & 0.994 & 0.390 \\
\hline \multirow[t]{2}{*}{ Média CONSADs Sudeste } & 0.602 & -0.146 & 1.644 & 0.104 & 1.042 & 0.250 \\
\hline & \multicolumn{6}{|c|}{ CONSADs Sul } \\
\hline CONSAD Alto Irani (AI) & 0.666 & 1.317 & 2.136 & 1.247 & 1.470 & -0.071 \\
\hline CONSAD Centro-Sul (CS) & 1.234 & 0.998 & 2.278 & 1.425 & 1.044 & 0.427 \\
\hline CONSAD Entre-Rios (ER) & 1.322 & 0.588 & 2.785 & 0.498 & 1.463 & -0.090 \\
\hline CONSAD Extremo Oeste Catarinense (EO) & 0.514 & 2.018 & 2.296 & 2.017 & 1.782 & -0.001 \\
\hline CONSAD Metropolitano Sul (MS) & 3.458 & -2.781 & 4.260 & -2.462 & 0.802 & 0.319 \\
\hline CONSAD Paraná Centro (PC) & -1.239 & 1.164 & 0.419 & 1.527 & 1.658 & 0.362 \\
\hline CONSAD Missões (MI) & 0.272 & 2.556 & 1.658 & 3.070 & 1.386 & 0.515 \\
\hline CONSAD Serra Catarinense (SC) & 0.234 & 0.580 & 1.382 & 0.942 & 1.148 & 0.362 \\
\hline Média CONSADs Sul & 0.808 & 0.805 & 2.152 & 1.033 & 1.344 & 0.228 \\
\hline
\end{tabular}

Fonte: Elaborado pela autora, segundo resultados da pesquisa.

Após calcular os índices, foi feita uma análise de clusters para identificar as trajetórias de desenvolvimento dos CONSADs, no período de 2000 a 2010. Na Figura 2, apresentam-se os clusters dos CONSADs, as regiões pertencentes a um mesmo grupo compartilham comportamentos semelhantes na evolução das características analisadas.

Observa-se que houve a divisão em quatro clusters, o cluster 1 está mais relacionado à dimensão 2 (índice populacional e meio ambiente), e a maioria são CONSADs das regiões Norte e Nordeste, regiões que apresentaram semelhança em sua evolução, confirmando os IDR apresentados anteriormente, onde as regiões Norte e Nordeste tiveram maiores valores nos índices populacional e meio ambiente. O cluster 2 está associado tanto à dimensão 1 quanto a dimensão 2 e estão presentes nesse clusters CONSADs da região Centro-Oeste, Sudeste e alguns das regiões Norte e Nordeste.

O cluster 3 é composto pela maioria dos CONSADs da região $\mathrm{Sul}$, e está mais relacionado a dimensão 1 (índice de bem estar e desenvolvimento econômico), corroborando com o IDR em que a região Sul foi a única que apresentou variação positiva no índice econômico. E, por último, o cluster 4 é formado por apenas um CONSAD (Metropolitano Sul pertencente a Rio Grande do Sul) e está associado mais a dimensão 1 que a dimensão 2 . Na tabela 5, mostram-se todos os CONSADs pertencentes a cada cluster. 


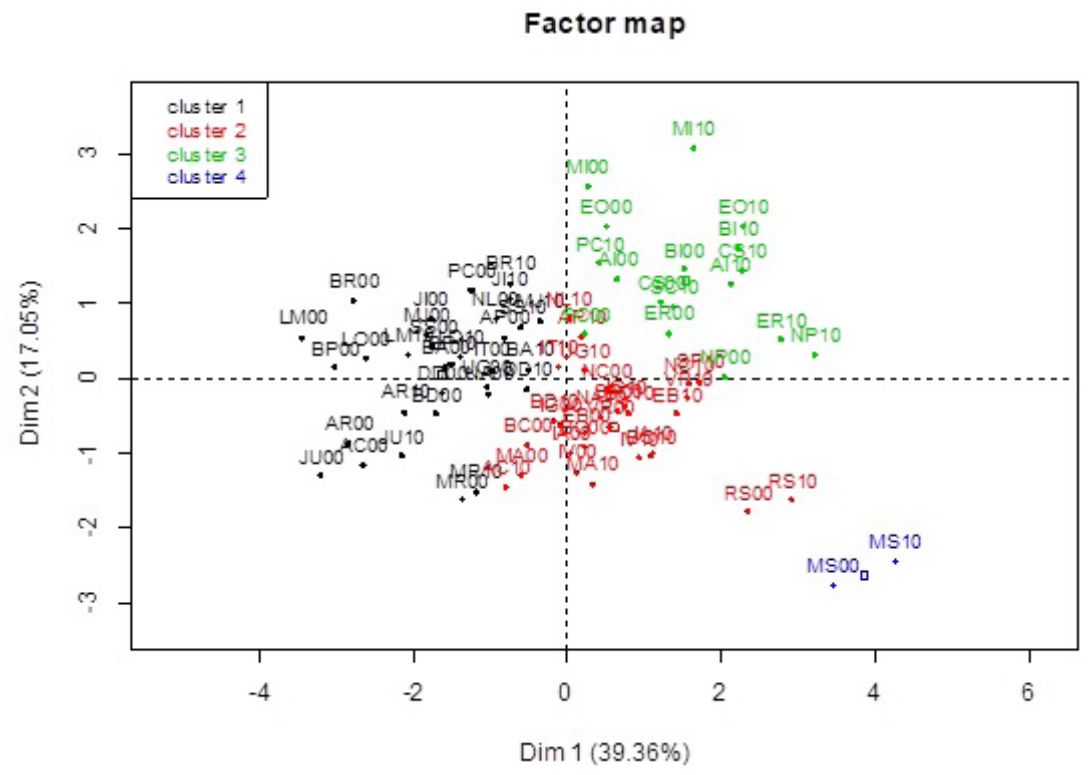

FIGURA 2 - Cluster dos CONSADs

Fonte: Elaborado pela autora, segundo resultados da pesquisa.

TABELA 5 - Cluster dos CONSADs

\begin{tabular}{|c|c|c|c|}
\hline Cluster 1 & Cluster 2 & Cluster 3 & Cluster 4 \\
\hline BR - Brumado (BA) & NC - Norte Capixaba (ES) & MI - Missões (RS) & $\begin{array}{l}\text { MS - Metropolitano } \\
\text { Sul (RS) }\end{array}$ \\
\hline LM - Lençóis Maranhense Baixo Parnaíba (MA) & BC - Baixada Cuiabana & EO - Extremo Oeste Catarinense (SC) & \\
\hline JI - Jiquiriça (BA) & RS - Rio Sul (RJ) & AI - Alto Irani (SC) & \\
\hline LO - Litoral Ocidental Maranhense (MA) & MA - Macapá (AP) & BI - Bacia do Itabapoana (RJ/ES/MG) & \\
\hline BP - Baixo Parnaíba Piauiense (PI) & VR - Vale do Ribeira (SP) & CS - Centro Sul (RS) & \\
\hline MJ - Médio Jequitinhonha (MG) & IA - Itambé (PE) & SC - Serra Catarinense (SC) & \\
\hline SS - Sertão de São Francisco (SE) & EB - Entorno de Brasília (DF) & ER - Entre Rios (PR) & \\
\hline $\mathrm{AR}$ - Arari (PA) & IV - Ivinhema (MS) & NP - Noroeste Paulista (SP) & \\
\hline JU - Juruá (AM) & SP - Sudoeste Paulista (SP) & PC - Paraná Centro (PR) & \\
\hline MR - Médio Rio Branco (RR) & IG - Iguatemi (MS) & & \\
\hline BA - Baturité (CE) & BO - Bodoquena (MS) & & \\
\hline DD - 7 de Dezembro (RO) & NL - Norte Litoral Paraibano (PB) & & \\
\hline BD - Bico do Papagaio (TO) & AP - Agreste Potiguar (RN) & & \\
\hline NL - Norte Litoral Paraibano (PB) & UG - Urucuia Grande Sertão (MG/GO) & & \\
\hline AP - Agreste Potiguar (RN) & AC - Alto Acre (AC) & & \\
\hline AC - Alto Acre (AC) & IT - Itaparica (PE) & & \\
\hline PC - Paraná Centro (PR) & NA - Norte de Alagoas (AL) & & \\
\hline UG - Urucuia Grande Sertão (MG/GO) & BD - Bico do Papagaio (TO) & & \\
\hline IT - Itaparica (PE) & & & \\
\hline NA - Norte de Alagoas (AL) & & & \\
\hline
\end{tabular}

Fonte: Elaborado pela autora, segundo resultados da pesquisa

Organizações Rurais \& Agroindustriais, Lavras, v. 20, n. 2, p. 114-133, 2018 
Desse modo, os dois métodos utilizados mostram a evolução nos CONSADs do Brasil, porém essa evolução não foi semelhante em todas as regiões, ou seja, CentroOeste teve evolução no IPOP, a região Sul no IDE, a Norte no IMA, e todas as regiões tiveram aumento no IBES, sendo assim, a estratégia do CONSAD de formação de capital humano foi benéfica para todos os CONSADs do Brasil.

De modo geral, os CONSADs tiveram aumento em quase todas as variáveis do IDR, apenas houve redução nas variáveis proporção de população rural, ocupados no setor agropecuário e a região Sudeste e Norte tiveram redução na renda per capita. Esses resultados mostram que essas pessoas saíram do campo para trabalhar na área urbana, em razão do aumento de empregados com carteira assinada, ocorrendo um desenvolvimento urbano nesses municípios.

\section{CONSIDERAÇÕES FINAIS}

O programa CONSAD do governo federal, criado em 2003, é um instrumento de política de combate à fome como contraponto às medidas emergenciais exigidas para o atendimento de populações ameaçadas pela desnutrição, voltando suas ações para a construção de bases sólidas que permitam às populações mais pobres obter trabalho e renda, mas será que houve melhoria em termos de desenvolvimento nos municípios pertencentes aos CONSAD entre os períodos de 2000 a 2010? Esta pesquisa procurou identificar se realmente houve um desenvolvimento desses municípios com a implantação do programa CONSAD, por meio do índice de desenvolvimento rural e análise fatorial múltipla, compostos por índices de bem-estar social, desenvolvimento econômico, populacional e meio ambiente.

Os resultados indicam que, em termos de desenvolvimento populacional, a maioria dos CONSADs diminuíram, apenas os CONSADs do Centro-Oeste apresentaram um pequeno aumento de 2000 a 2010. A redução das demais regiões foi decorrente da variável proporção da população rural que diminui, ou seja, a quantidade de pessoas morando na região rural reduziu de 2000 para 2010, reduziu a capacidade do município em reter população rural. A região que obteve o menor e maior IPOP foi Centro-Oeste e Nordeste, respectivamente, ou seja, mesmo a região Centro-Oeste apresentando um pequeno aumento ainda continua com os menores IPOP entre os CONSADs.

No aspecto de bem estar social, os CONSADs tiveram aumento de 2000 a 2010, mostrando uma melhora no bem-estar social da população dos CONSADs, todas as variáveis pertencentes ao índice aumentaram, evidenciando uma melhora em termos educacionais e infraestrutura domiciliar, as regiões que tiveram um maior e menor índice em 2010 foram Sudeste e Norte, respectivamente. Contudo, os CONSADs da região Norte tiveram os maiores valores de evolução de 2000 a 2010 no bem estar social.

No índice de desenvolvimento econômico, apenas os CONSADs do Sul aumentaram, já nas outras regiões o índice diminuiu de 2000 a 2010, isso é decorrente da variável ocupados no setor agropecuário que reduziu em todos os CONSADs, ou seja, houve uma redução do emprego no setor agropecuário, em razão do aumento da mecanização, porém houve um aumento no emprego com carteira assinada em outros setores.

No índice de meio ambiente os valores dos CONSADs diminuíram de 2000 a 2010, isso foi decorrente da variável ausência de monocultura que reduziu, evidenciando a adoção de uma ou poucas culturas "modernas" que são grandes consumidoras de agrotóxicos. A região Sudeste foi a que obteve o menor IMA. E alguns CONSADs do Norte e Nordeste tiveram um aumento, mostrando que o programa foi benéfico para essas regiões no setor de meio ambiente, estimulando a agricultura familiar e preservação do solo.

No Índice de Desenvolvimento Rural, tanto em 2000 quanto em 2010, a região que apresentou maiores valores foi a Sudeste, seguida pela Sul, Centro-Oeste, Nordeste e, por último, Norte. Apesar de essas últimas regiões apresentarem os menores IDR, foram as que obtiveram maiores aumento na trajetória de 2000 a 2010, a região Norte aumentou 8,6\% e Nordeste 7,4\%.

Dentre os 40 CONSADs analisados, apenas 4 apresentaram redução no IDR, são eles: CONSAD Jiquiriça na Bahia, Noroeste Paulista e Sudoeste Paulista em São Paulo e o Entre Rios no Paraná, mostrando que o programa do CONSAD não foi benéfico para essas quatro regiões. Os 10 CONSADs que tiveram os maiores aumento no IDR pertencem às regiões Norte e Nordeste, sendo assim, aceitou-se a hipótese desse trabalho na qual consta que as regiões Norte e Nordeste tenderiam a apresentar maiores evoluções do IDR nos anos 2000 e 2010.

Portanto, os municípios dos CONSADs, de modo geral, tiveram um aumento no desenvolvimento rural nos anos 2000 a 2010, o aspecto que mais impulsionou esse aumento foi à melhora no bem estar social. Sendo assim, pode-se concluir que o programa é benéfico para a maioria dos municípios dos CONSADs, houve uma melhora na educação, infraestrutura domiciliar, aumento da renda 
per capita, aumento na taxa de envelhecimento, redução da população na área rural e aumento de empregados com carteira assinada. Contudo, fica como sugestão de políticas públicas para essas localidades o estímulo à agricultura familiar, que reduziu, ao longo desses anos analisados, lembrando que um dos objetivos dos CONSAD é estimular a agricultura familiar como forma de gerar segurança alimentar para esses municípios. É importante destacar que os dados desta pesquisa são referentes a toda população de determinado município, não há descriminação entre população rural e urbana, isso pode levar a discrepância de dados, desse modo, fica como sugestão para trabalhos futuros uma pesquisa de campo para analisar a evolução da área rural dessas localidades.

\section{REFERÊNCIAS BIBLIOGRÁFICAS}

CAMPOS, S. A. et al. Trajetória de modernização da agropecuária mineira no período de 1996 a 2006. Revista economia aplicada, 2014, vol. 18, n.4, 717-739.

CUNHA, C. G. S. Avaliação de políticas públicas e programas governamentais: tendências recentes e experiências no Brasil. Universidade Federal do Pará, 2006.

DIEESE. Estudos e pesquisas: O mercado de trabalho assalariado rural brasileiro. 2014.

ESCOFIER, B. \& PAGÉS, J. (1984), L’analyse factorielle multiple: une méthode de

comparaison de groupes de variables, in S. R.R., D. E., E. Y., L. L. \& J. Pagès, eds, 'Data Analysis and Informatics III', North-Holland, pp. 4-55.

HAIR, J., et al. Multivariate Data Analysis: with readings. Prentice Hall, New Jersey. 1995.

HAIR JUNIOR et al. Análise multivariada de dados. Porto Alegre: Bookman, 2005.

JANUZZI, P. M. Considerações sobre o uso, mau uso e abuso dos indicadores sociais na formulação e avaliação de políticas públicas municipais. Revista de Administração Pública - Fundação Getúlio Vargas. Rio de Janeiro, 2001.

JESUS, C. M. Desenvolvimento territorial no Brasil: a experiência dos Consórcios de Segurança Alimentar e Desenvolvimento Local. Dissertação apresentada ao Instituto de Economia da Universidade Federal de Uberlândia. Uberlândia, 2006.

KAGEYAMA, A. Desenvolvimento rural: conceito e um exemplo de medida. In: XLII Congresso da Sociedade Brasileira de Economia e Sociologia Rural, 2004, Cuiabá. "Dinâmicas Setoriais e Desenvolvimento Regional".

MARTINS, C. L. Indicadores de desenvolvimento rural para os territórios consad de Mato Grosso do Sul. Programa de pós-graduação strictu sensu em administração na Universidade Federal de Mato Grosso do Sul. Campo Grande, MS, 2011.

MDS. Guia do CONSAD. Trabalho Elaborado pelo Núcleo de Economia Local da Área de Desenvolvimento Econômico e Social do IBAM para o Ministério do Desenvolvimento Social e Combate à Fome - MDS. Agosto, 2004.

MELO, R. F. Análise do desenvolvimento rural na região do Triângulo Mineiro e Alto Paranaíba: caracterização dos municípios com base em indicadores populacionais, econômicos, ambientais e de bem-estar social. Dissertação de Mestrado apresentada ao Instituto de Economia da Universidade Federal de Uberlândia. Uberlândia, MG, 2005.

ORTEGA, A. C. Desenvolvimento territorial rural no Brasil: limites e potencialidades dos CONSADs. Rev. Econ. Sociol. Rural vol.45 no.2 Brasília, Abril 2007.

PAGÉS, J. Multiple fator analysis: main features and aplication to sensory data. Revista Colombiana de Estatística, v. 27, n. 01, 2004.

RIANI, F. Economia do setor público: uma abordagem introdutória. 5. Ed. Rio de Janeiro: LTC, 2009.

PRADO, D. V. Consórcios públicos: análise do instrumento sob a perspectiva da ação orçamentária Consad, executada pela Secretaria Nacional de Segurança Alimentar (Sesan) do Ministério do Desenvolvimento Social e Combate à Fome (MDS). Escola Nacional de Saúde Pública Sergio Arouca ENSP, Brasília, 2011.

SILVA, F. F., 2006. Distribuição de crédito para a agricultura familiar: um estudo do PRONAF a partir de um indicador de Desenvolvimento Rural. Dissertação de Mestrado apresentada ao Instituto de Economia da Universidade Federal de Uberlândia. Uberlândia, MG. 
SILVA, S. P.; LEITE, L. M. Transbordamentos de pobreza e desigualdade em minas gerais: a fronteira interestadual importa? Uma análise econométrica-espacial. UFMG, 2014.
ZIMMERMANN, C. L. Monocultura e transgenia: impactos ambientais e insegurança alimentar. Veredas do direito, Belo Horizonte, v. 6, nº 12, 2009. 